\title{
Experimental Teaching Reform on the Fly-By-Wire System of Aircraft Based on Engineering Practice
}

\author{
H.F. DONG, Z.B. SHI, Y.B. HE \\ Aeronautical Automation College, Civil Aviation University of China, Tianjin China
}

\begin{abstract}
With the rapidly development of civil aviation and a large number of introduction of new models and technologies, higher requirements are put forward to the number and quality of aircraft maintenance personnel. Following the construction of Tianjin's brand major-Electrical Engineering and Automation, combining with the Excellent engineer education and training programs of our school, research and exploration on experimental teaching reform for the course of Fly-By-Wire(FBW) of aircraft is done based on the concept of CDIO in this paper, which is guided by the demand for knowledge of engineering practice. It is enable students to develop engineering thinking patterns and aircraft maintenance awareness, increase the ability of learning, thinking and analytical problem reversely, so that to enhance their competitiveness of employability and adaptability of work.
\end{abstract}

KEYWORD: Fly-By-Wire; engineering practice; aircraft maintenance; CDIO; teaching reform

\section{INTRODUCTION}

With the rapid development of China's civil aviation industry, and the introduction of a number of new technologies, new aircraft models, the quantity and quality of aircraft repair personnel have put forward higher requirements. At present, maintenance technology is seriously inadequate, repair personnel level is uneven, the number of engineering and technical personnel in the domestic repair enterprise is only $25 \%$ compared with the foreign similar scale aviation repair company. Currently the most shortage is airline maintenance personnel. In order to improve the repair efficiency, reduce the labor costs, maximize the economic benefits of airlines, a solid theoretical foundation, a wide range of professional repair, skilled, strong practical ability are required to airline maintenance personnel. In order to meet the growing market for aviation repair personnel needs and cultivate high quality talent, combining with our school " program of educating and training excellent engineers ", based on the concept of CDIO (Li2011, Yin2011, Marasco2013, Svensson2012), large-scale improvement and construction is carried out in the aspects of training plan, curriculum system, laboratory construction, then the civil aviation maintenance and management quality is improved, students' repair theory is strengthened, the competitiveness of employment market is enhanced.
With the introduction of new models A380 and B787, and extensive use of the Fly-By-Wire system, it is necessary to strengthen the experimental development and comprehensive reform for Fly-ByWire system course, enhance students' experimental operation and ability of practice, making a deep theoretical foundation for the development of new technology for actuator used power by wire.

Based on above analysis, in order to learn aircraft related knowledge and adapt to the needs of aviation maintenance work for the aviation electrical and automation students, the Fly-By-Wire theory teaching is not only strengthen in classroom, but also experiment teaching is pay attention to, combining the classroom theoretical knowledge with practical operation is the supporting with the our major and the comprehensive practice to the disciplines, and is the condition of high quality engineering talent cultivation conditions. Only strengthening the experimental teaching links and practical operation ability can adapt to the demand for professional talents of the aviation maintenance. Therefore, around the goal of building a professional electrical engineering and automation Tianjin City professional brand, the reform and practice of experimental teaching content and method for the Fly-By-Wire of Aircraft is actively carried out. 


\section{REFORM AND OPTIMIZE THE TEACHING CONTENT OF EXPERIMENTAL COURSE}

First establishing the object of the reform on experimental teaching content, which is the cultivation goal of applied type aviation maintenance personnel (Yan2008). The organization of experiment teaching content is based on the necessary basic theory, prominent learning practical of the Fly-By-Wire system for electrical and automation professional, strengthen the connection of course and flight control.

The experiment instruction book is written around on the Fly-By-Wire system modeling, system of integrated design and analysis, actively cooperating with the theory of teaching. The engineering background is emphasized; the cultivation of practice ability is outstood. In accordance with the teaching syllabus, lesson plans is given according to the characteristics of each module, form following the teaching contents is required, the teaching content is highlight, both concise and integrity, standard and diversity, the efficiency of classroom theory teaching is improved, large amount of information is given to ensure the quality of teaching.

\subsection{Optimization content of experimental teaching, strengthening practice of Fly-By-Wire system}

First of all, Fly-By-Wire system demonstration is carried out by taking A320 aircraft as the prototype, A320 aircraft pitch control chart as follow Figure 1.

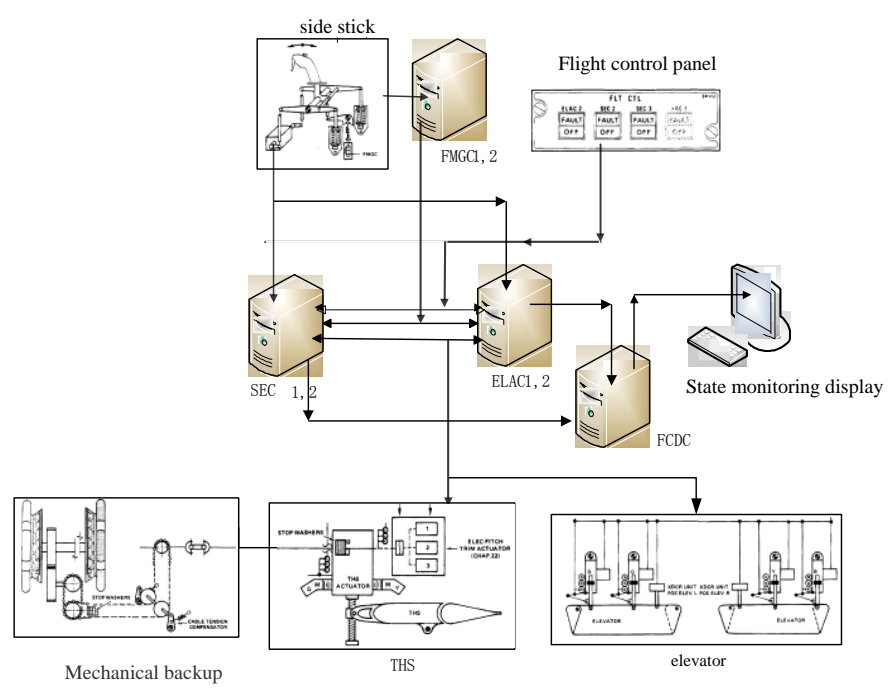

Figure 1. A320 Aircraft pitch control block.

\subsection{Optimization of experimental teaching outline, enhancing practice teaching}

According to the view of understanding and cognitive point, in order to cooperate and sublimate theory teaching, experimental project is designed, then teaching quality is improved.
According to the existing teaching and experimental conditions, in line with the view of system and the perspective of understanding, the experimental design is given by the virtual simulation platform, to simulate control flight control surface. Practice time is limit; several experimental teaching is designed for choice: FBW control law design and verification, simulation and analysis of Fly-By-Wire control system, demonstration of control process for flight control surface, component location identification.

\subsection{Preparation of experimental teaching plans}

According to the content of experiment teaching, each module of the experimental lesson plans is given, aircraft control surface is actuated and various aircraft flight attitude response are displayed by flash, the rich picture and large amount of information can stimulate students interest in studying, and make the experimental teaching convenience and high efficiency, then the quality of experimental teaching is ensured.

\section{IMPROVING EXPERIMENT TEACHING METHOD}

\subsection{Guide the students to participate in the activities of scientific research}

The cultivation of innovative talents, the main is to develop high quality comprehensive type with innovative consciousness and innovative thinking talents (Zhang2010). "Delegate to fish, as delegated by the fishing", methods is more important than the outcome, students is actively guide to participate in scientific research activities, the cultivation of innovative talents is then comprehensively promoted.

Taking teaching as the center, continuously improving the quality of teaching is the eternal theme of teaching and scientific research is to improve the quality of teaching of the propeller, scientific research promoting teaching aims at cultivating the teaching quality with innovation ability. Based on this concept, the students are actively guided into the study of scientific research project undertaken by teachers, which is provincial and ministerial level project, the research content and results of the project are introduced into classroom teaching as a teaching case, the classroom teaching content is then enrich and the quality of course is improved, the latest knowledge and information is passed to students so as to broaden their horizons, and the teachers' research papers published is given as an extracurricular reading materials to improve the teaching depth and breadth.

Take Fly-By-Wire control course as the center, to guide the students participate in scientific research project, the project is divided into sub projects which 
students can participate in the module, different grades students constitute scientific research group, the formation of students' scientific research echelon, and at the same time for poor academic performance of student involvement, to enhance the enthusiasm, their self-confidence and learning guide actively, training model engineering talents with innovative ability.

With the central university fund project, the students have completed independent steering control for the patrol car steering wheel (Figure 2), the understanding on the direction of servo control is deepen, there are 2 second grade students, 2 third grade students and one fourth grade student, formed a small scientific research echelon, it got a good effect.

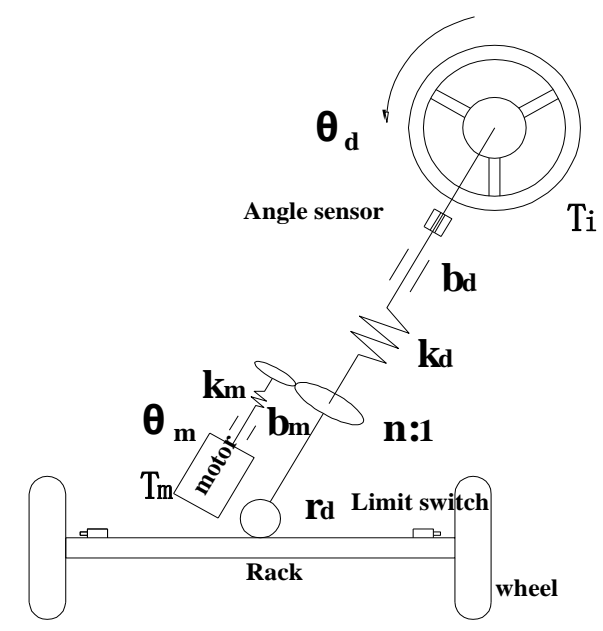

Figure 2. Structure of the autonomous steering system.

Steering control system is adopted single-chip microcomputer 89C51F340 to control the servo DC permanent magnet motor, speed is reduced by the planetary gear box, mechanical steering column is driven to rotate by gearbox output shaft through a gear meshing, the movement is driven through a universal joint and gear rack connected structure, finally make the wheel around kingpin produce a certain swing angle, steering is realized.

\subsection{Project teaching method of using the experiment as the center}

Exploration on teaching mode take experiment teaching as the center, the item teaching method is used (Zhu2012, Ding2005). We pay attention to the link between the theory and engineering practice, to increase students' interest in learning. The project teaching method is to take the task as the center to choose and organize the contents of experimental courses, and the main way of learning the course mode is to complete the task, the correlation between the experimental contents and work to strengthen the integration of theory and practice, the efficiency about professional ability of the students is improved, the cultivation of applied talents are completed.
In the experimental class began, several experimental projects is to assign students closely related to curriculum, students can finish alone or with others, the project is completed at the end of the experiment course, the project completion can be the part of the experimental examination for students, so as to arouse the students' enthusiasm of practice to achieve the combination of theory and practice. At the same time, let the students participate in the FlyBy-Wire laboratory construction, which is divided into task module, the subtask is completed under the guidance of teachers, practical ability and scientific research ability is strengthen.

\section{REFORM AND OPTIMIZATION OF EXPERIMENTAL TEACHING}

According to the view of understanding and cognitive point, in order to cooperate and sublimate theory teaching, experimental project is designed, then teaching quality is improved. Combined with a Fly-By-Wire laboratory construction, course design is set up for Fly-By-Wire system of aircraft, comprehensive experiment device is developed, the comprehensive design ability is cultivated, and we pay attention to personality development of students and encourage innovation.

The experimental teaching system and methods is researched(Liu2010, Chen2010), in order to cultivate students' ability, the student can study through the autonomous learning, cooperative learning and research learning, which is researching experimental teaching, students' practical and innovation ability is then trained and the experimental teaching level and teaching effect are improved. Constructing experimental teaching system is to cultivate students with experimental skills, good engineering and innovation consciousness, heighten students' ability to discover, analyze and solve problems, and expand the students' comprehensive quality. In the experimental teaching, the autonomy and practical of students is emphasized, no longer emphasizes the teacher's authority, the teacher is learning guider, we pay attention to cultivate the students' ability of practice and innovation, strive to improve the environment of innovation and independent initiative fully mobilized for students, build a new system of experimental teaching.

According to the experimental program, improving experimental instruction, actively cooperate with the theory of teaching.

The virtual experiment verification and Simulation is given before the laboratory is built, for aircraft demonstration experiment, experiment report data tables is designed, the range of parameters related to the system are given, and parameters and in operation problems are recorded, analyze the problem is analyzed and correct. 
According to the given Fly-By-Wire mathematical model, the control law design and verification is realized by the simulation software, the simulation results are given under the condition of different control law.

For redundancy reliability experiment of Fly-ByWire, redundant control model is established in simulation software, the design results of different redundancy fault-tolerant control is verified, the handling performance is given under the condition of Fail/ Operation and Fail/Safe mode. Design report data tables, and record the related parameters in operation; A320 CBT experiment is done to familiar with the working principles and position of components

\section{CONCLUSIONS}

Based on engineering practice to knowledge requirements, exploration and practice of the experimental teaching reform of aircraft FBW is carried out, and the project teaching method is actively introduced taking experiment as the center, the students is guided to participate in the activities of scientific research. We explore the research on experimental teaching system and methods, the engineering thinking mode and aircraft maintenance consciousness is established, the reverse thinking skills of thinking, analyzing and solving problems are integrated to improve. We pay attention to personality development and cultivate comprehensive design ability of students, encourage innovation to enhance the competitiveness of employment and job adaptability.

\section{ACKNOWLEDGEMENT}

This work was funded by the Teaching Reform Project for Civil Aviation University of China (2013 - 53)

\section{REFERENCES}

[1] Chen Ling, PENG Chenghong. Enhancing Researching Based Experimental Teaching to Cultivate Students Innovational Ability. Research and Exploration in Laboratory, 2010, Vol. 29.No.8, pp: 202-204.

[2] Ding Yong, WANG Congqin. Teaching Reform and Practice in the Course of Automatic Control Principles. Journal of Nanjing University of Aeronautics and Astronautics, 2005, Vol.7. No.1, pp: 84-86.

[3] Liu Dunwen, YANG Guang. Study-based Teaching for Experimental Courses of Safety Engineering Specialty and Cultivation of Innovative Talents. China Safety Science Journal, 2010, Vol. 20. No.5, pp: 157-161.

[4] Li Wenjing, Zhang Chunming, etc. Reformation and exploration of higher engineering education based on CDIO syllabus. Lecture Notes in Electrical Engineering, v 112 LNEE, p 587-591, 2011.

[5] Marasco Emily, Behjat Laleh. Integrating creativity into elementary electrical engineering education using CDIO and project-based learning. 2013 IEEE International Conference on Microelectronic Systems Education, MSE 2013, p 44-47, 2013.

[6] Svensson Tomas, Gunnarsson Svante. A Design-BuildTest course in electronics based on the CDIO framework for engineering education. International Journal of Electrical Engineering Education, October 2012 v 49, n 4, p 349-364.

[7] Yin Niansheng, Yu, Hanqi, etc. Reform and practice of schools and enterprises build CDIO engineering education mode. Engineering Education and Management. Vol 2, p 45-48, 2011.

[8] Yan Zhaohua. Research and Practice of Teaching Innovation of Human Engineering Course. Journal of Hefei University, 2008.Vol. 25.No.4, pp: 113-116.

[9] Zhang Wenting, Wang Ziting. Research and Exploration on Teaching Reformation for Circuit-Analysis Experimental Course. Research and Exploration in Laboratory, 2010, Vol. 29. No.5, pp: 146-148.

[10] Zhu Feng. A Study of Project Teaching Approach in China-Also on Applicability of Project Teaching Approach to Foreign Language Teaching in China. Theory and Practice of Education, 2012, Vol.30. No.9, pp: 54-56. 